\title{
Cardiovascular System Findings Elapsed Time
}

National Cancer Institute

\section{Source}

National Cancer Institute. Cardiovascular System Findings Elapsed Time. NCI Thesaurus.

Code C123953.

The interval between two cardiovascular system measurement reference time points. 